\section{Endangered species}

SIR - Christopher Anderson's article about the hazards of reintroducing endangered species ${ }^{1}$ is timely, given current interest in the role of disease in population dynamics and conservation. But I think he may have spoken with an unusual subset of biologists in coming to the conclusion that most researchers in the area believe that maintaining maximum genetic diversity in wild populations by release of captive animals outweighs the potential costs of simultaneously introducing new pathogens that might extinguish the wild population.

It is very difficult to find evidence that any wild population is in danger of extinction because of lack of genetic heterogeneity ${ }^{2}$. We also know of several species whose populations have increased and are surviving now despite extreme homogeneity. The cheetah Acinonyx jubatus is an example. It is so genetically homogeneous that animals from south and west Africa reciprocally accept skin grafts $^{3}$, yet it survives throughout Africa. In fact, it is beginning to look as if demographic and environmental stochasticity are usually more important problems for small isolated populations than is lack of genetic diversity ${ }^{4}$. And of course, if a wild population is in danger for genetic or demographic or ecological reasons, then in most cases the factors that brought it to that state are probably the real threat, not those biological problems.

To take just one example, the Virunga mountain gorilla population Gorilla gorilla numbers about 300 animals, that is, far less than the commonly quoted figure of 500 for large mammals. Even with an effective population size of only

\section{Cheap big science}

SIR - In Sir Mark Richmond's speech "A future for British science" (Nature 353, 379; 1991), he states: "Some research topics are so expensive (or otherwise demanding) that only a few institutions are able to participate in them. Examples are astronomy (at least when it requires large telescopes). . .". In fact, the opposite is true. Large telescopes are now national or international facilities largely equipped with common-user instrumentation, and any astronomer with a good research programme can use them. There are advantages in being in a large department but it is not a necessity.

Astronomy Centre,

R. J. TAYLER

Division of Physics \& Astronomy,

University of Sussex,

Falmer, Brighton BN1 9QH, UK
50 breeding animals, more than 100 years will pass before genetic heterogeneity is reduced by 10 per cent. In those 100 years, the local human population will, at current rates of population increase, have doubled, and doubled again. In these circumstances, it would be absurd to count loss of genetic heterogeneity as a threat to the gorilla population ${ }^{5}$; and the same goes for many of the threatened populations of wild species that zoos would try to save by release of captive-bred individuals.

The new findings reported by Anderson ${ }^{1}$ confirm what many conservationists have feared all along, namely that the dangers of introduction of disease into wild populations are so high that reintroduction should be a last-ditch solution. Well-run zoos can benefit conservation in many ways; they do not need reintroduction as their grounds for existence, as so many appear to think. Perhaps their main justification is that they encourage the interest in animals that leads to conservation in its rightful (and cheapest) place, namely in the wild.

Department of Anthropology, SANDY HARCOURT

University of California,

Davis, California 95616, USA

1. Anderson. C. Nature 351, 89 (1991)

2. Allendorf, F.W. \& Leary, R.F. in Consenvation Biology. The Science of Scarcity and Diversity (ed. Soulé, M.E.) (Sinauer Associates, Sunderland, Massachussetts, 1986).

3. O'Brien, S.J. Goldman, D., Merril, C.R., Bush, M. \& Wildt D.E. Science 221, 459-462 (1983).

4. Lande, R. Science 241, 1455-1460 (1988).

5. Harcourt, A.H. in Primates. The Road to Self-Sustaining Populations (ed. Benirshke, K.) (Springer. New York, 1986).

\section{Pseudogenes}

SIR - It has been said that humans are a gene's way of making more genes. I propose that the modern streetwise gene's way of assuring its future is the Human Genome Project.

The mapping project will imbue all the sequenced genes with a fitness of 100 per cent. That is, every single sequence will be faithfully preserved and duplicated into eternity. The only selective pressure exerted on a gene will come from scientists who suspect it of causing disease or who seek to use it to cure illness. Such genes might be mutated to accommodate society's healthcare goals. Those genes with interesting biology will out-compete their mundane colleagues for in vitro and in vivo expression and, more importantly, for scientific inquiry and funding.

With regard to proliferation, genes with widely distributed homology or interesting functions are likely to be copied from central databases onto individual floppies. These sequences might then be expressed on the screens of countless computers, and even back into animals as transgenes.

As every gene would be individually and directly responsible for its own survival in the database, there would be no need for sex and reassortment to move the gene into a more favourable genetic individual, species or environment. The mixing-and-matching could all be done in computer files.

Interesting rivalries might arise between genes and pseudogenes that had been silenced in the organism. Now, pseudogenes would be as readily expressed on a video screen as the active sequence.

Finally, the very core of natural selection would be imploded. Random mutations could arise by computer error or interestingly enough, cosmic rays, magnetic fields and other forces capable of disturbing storage devices. The ideal genomic database would have a genetic drift of zero.

\section{David Mahoney Institute}

IBRAHIM A. TANGOREN of Neurological Sciences,

University of Pennsy/vania

School of Medicine,

107 Johnson Pavilion

34th and Spruce Streets,

Philadelphia, Pennsylvania 10104, USA

\section{Meanings}

SIR - Philological discussions (Nature 351, $179 \&$ 352, 751; 1991) are interesting in their own right but philology does not dictate or define the meaning of words; meanings are defined by usage. Mutant and recombinant may have been invented by scientists without a knowledge of language, but these words now have clear meanings. Of greater concern to scientists who care about language should be the overuse of words in ways that destroy meaning. Woe betide anyone who wishes to describe a parameter, whose proper meaning is quite clear but which is used instead of a variable or a limit; and poor paradigm has come to mean no more than example. The overuse of demographic as an adjective applied to the ages and weights of a dozen or so patients studied in a medical research project will soon force epidemiologists to invent another word for true demographic studies. Even worse confusion will come of the increasing habit, especially in US journals, of describing patients entered into studies not as the sample but as the population. Statisticians had better start looking for new words to distinguish between sample and population statistics.

NEVILLE W. GoOdMan

\section{Department of Anaesthesia,}

University of Bristol and Southmead Hospital,

Bristol BS10 5NB, UK 